\title{
IDENTIFICAÇÃO COLORIMÉTRICA EM CITRUS
}

Osvaldo Bacchi

\section{INTRODUÇÃO}

A moléstia dos citrus, inicialmente denominada "podridão das radicelas", hoje, mui acertadamente, batizada com o nome de "tristeza", vem devastando pomares paulistas e fluminenses, de maneira assustadora, a ponto de constituir, no momento, problema de magna importância para a citricultura nacional.

$O$ fato da "tristeza" ter sido verificada sòmente em laranjeiras (e limoeiros ?), cujos "cavalos" são de $C$. aurantium L., constitue particularidade notável desta moléstia. Parece indicar até, tratar-se do mesmo mal que, em Java e África do Sul, impede se formem pomares sôbre "cavalo" de $C$. aurantium L e que, na Argentina, exterminou aquêles formados sôbre idêntico "cavalo".

O estudo da suscetibilidade dos diferentes "cavalos" apenas tem sido realizado satisfatòriamente, nos poucos pomares das Estações Experimentais da Divisão de Experimentação e Pesquisas (Instituto Agronômico). Nas plantações particulares, ora pela carência de dados sôbre plantio, ora pela falta de escrúpulo de alguns viveiristas, a identificação do porta-enxêrto só tem sido possível quando há brotações esporádicas (ladrões). Assim, freqùentemente ficamos em dúvida quanto à sua identidade, não sendo possível saber sôbre a suscetibilidade ou não das outras variedades.

Tivemos necessidade, portanto, de lançar mão de um processo rápido de identificação do "cavalo" usado. Em vista dos resultados satisfatórios obtidos em outros paises citricultores com o método colorimétrico, decidimo-nos tentar o seu emprêgo.

No presente trabalho, realizado com material de alguns dos principais municípios citrícolas do Estado de São Paulo, damos os resultados das observações feitas e algumas considerações de caráter geral.

\section{BREVE REVISÃO DA LITERATURA}

Baseando-se na quantidade variável de glucosídeos encontrada nas raízes dos citrus e no fato dêstes glucosídeos conterem fenóis, Hendriksen (3) fez, em 1928, as primeiras tentativas de determinação colorimétrica em Citrus. $O$ seu método consistia: tratar um extrato aquoso de raízes frescas e moídas, com cloreto férrico. Das quatro variedades experimentadas (laranjas azêda e doce, grapefruit selvagem e limão rugoso), êsts método apenas deu algum resultado com o limão rugoso. 
Mais tarde, Halma e Haas (1) realizaram com as mesmas variedades acima, novas experiências de identificação, com o emprêgo de numerosos reagentes químicos e com o extrato aquoso da casca do tronco, sêca $e$ moída. De todos os reagentes usados, o que melhores resultados, deu, foi o de Almen, que é recomendado para os ácidos carbólico e salicílico. Êste método parece ser suficiente para a identificação das quatro espécies examinadas; Halma e Haas (1) mencionam, entretanto, os reagentes molibdato de amôneo, cloreto férrico e cloreto titanoso, que poderão ser usados em determinações suplementares, para auxiliarem e confirmarem as observações feitas com o reativo de Almen.

Halma (2) pouco tempo depois introduziu uma modificação no processo de Almen, que vantajosamente requer menor quantidade de extrato, $e$, por conseguinte, menor porção de casca. Maiores diferenças colorimétricas em menor espaço de tempo, vêm em refôrço desta modificação.

Um trabalho bastante extenso sôbre o assunto, foi realizado, mais recentemente, por Marloth (4). Trabalhando na África do Sul, com os mesmos reagentes usados por Halma e Haas (1) na Califórnia (U.S.A.), obteve a identificação de quase tôdas as 15 diferentes espécies e variedades examinadas.

\section{MATERIAL E MÉTODO}

Iniciamos o nosso trabalho, fazendo uso da casca tirada logo acima do colo da planta. Isto trazia certos inconvenientes: a) prejudicava bastante a planta, que, na maioria das vêzes, pertencia a ensaios experimentais; b) incerteza, em alguns casos, de que se estava tomando material do "cavalo", em virtude de não se poder precisar a região do enxêrto; c) possibilidade dos sais, empregados como preventivos nos troncos, influirem na reação. Em vista disso, resolvemos passar a empregar casca de raiz, com a qual desapareceriam as desvantagens acima enumeradas. Devemos lembrar, entretanto, que os resultados foram idênticos, quer usando-se casca do tronco, quer da raiz.

As primeiras determinações foram feitas com material colhido em Campinas; passamos, em seguida, a trabalhar com cascas de raiz coletadas em Limeira, Piracicaba e Ribeirão Preto. Demos, sempre, preferência aos "cavalos", cujos enxertos eram de laranjas doces (baía, baianinha, barão, pera, etc.) (C. sinensis Osbeck), que correspondem d̀s combinações encontradiças nas culturas, $e$, portanto, as que mais nos interessavam. Fizemos, também, algumas determinações em pés francos e em "cavalos" enxertados com limão Eureca; obtivemos, em todos êles, os mesmos resultados.

Quanto ao material usado, para facilidade de exposição, separamo-lo em dois grupos. No primeiro colocamos as seguintes espécies e variedades, que mais nos interessam e que constituem todos os "cavalos" possivelmente empregados no Estado: laranjas caipira e lima ( $C$. sinensis Osbeck); limões rugosos da Flórida e nacional, ponderosa e gigante (C. limonia Osbeck); laranjas agro-sevilhana e agro-doce (C. aurantium 
L.) ; tangerina cravo (C. nobilis Lour.); lima da Pérsia e limão cravo (C. aurantifolia Swingle); pomelo (C. paradisi Macf.) e Poncirus trifoliata Raf.. Incluimos no outro grupo, as espécies e variedades abaixo enumeradas, cujas observações foram realizadas, apenas para uma comparação mais completa entre os nossos resultados e os obtidos por Marloth (4) : limões eureca e siciliano (C. limonia Osbeck) ; toranja vermelha (C. maxima Merril) ; cidra (C. medica L.); kunquat Nagami (Fortunela margarita Swingle); tangelo (híbrido) e citrangequat (híbrido).

As observações feitas com as amostras dêste segundo grupo, não entram, portanto, nas considerações no texto. Apenas utilizamos os dados referentes às variedades eureca e siciliano (Fig. 4) na discussão sôbre a espécie $C$. limonia Osbeck.

O método por nós usado foi o mesmo estabelecido por Halma e Haas (2), ou seja : colhêr um pedaço de casca do tronco ou da raiz, que seja suficiente para dar $0,5 \mathrm{gr}$ de pó. Deve-se fazer prèviamente, uma ligeira raspagem superficial, para eliminar as impuresas presentes. (As nossas amostras sofriam, no laboratório, uma limpesa ainda mais minuciosa das substâncias extranhas). Depois de sêco em um forno, à temperatura de $70^{\circ}$ C., o material é moído em gral de porcelana e passado por uma peneira 40. Do pó assim obtido, tomam-se 0,5 gr em um vaso da Boêmia e ajuntam-se $20 \mathrm{cc}$ de água distilada. Alguns minutos depois, filtra-se a solução, lavando-se o resíduo do filtro com mais $10 \mathrm{cc}$ de água.

Em virtude da embebição pelo papel de filtro e pelo próprio pó, obtêm-se mais ou menos $27 \mathrm{cc}$ de extrato, que serão suficientes para 5 determinações, uma vez que se usem, para cada uma delas, 5 cc de extrato.

Reagentes. Os reagentes indicados por Halma e Haas (1), que também foram usados por Marloth (4), são, como já foi mencionado atrás, em número de quatro: o de Almen; molibdato de amôneo; cloreto férrico e cloreto titanoso.

Vejamos, como estes reagentes devem ser preparados e usados (2) (4).

$O$ reagente de Almen é pràticamente o mesmo de Millon para albuminas e fenóis. O seu grau de sensibilidade é de 1:400.000.

Prepara-se do seguinte modo: dissolvem-se $160 \mathrm{gr}$ de mercúrio metálico para análise em $160 \mathrm{gr}$ de ácido nítrico fumegante (usamos o de densidade 1,52) ; acrescentam-se, depois de completada a reação, $320 \mathrm{cc}$ de agua distilada. Obtem-se, por fim, o reagente, eliminando-se por decantação o precipitado amarelo que se forma.

Para o seu emprêgo tomam-se $5 \mathrm{cc}$ do extrato aquoso de casca em tubo de ensaio, acrescentam-se 2 gotas de hidróxido de potássio (empregamos a 10\%) e 10 gotas de uma solução saturada de sulfato de cobre. Colocam-se, em seguida, 10 gotas do reagente e ferve-se em banho-maria durante alguns minutos. $O$ exame poderá ser feito logo depois, sendo, entretanto, vantajoso esperar que o precipitado formado se deposite, para se poder realizar um exame mais criterioso.

Prepara-se o molibdato de amôneo, dissolvendo-se $100 \mathrm{gr}$ de ácido molíbdico em uma mistura de $144 \mathrm{cc}$ de hidróxido de amôneo e 271 cc de água distilada. Despeja-se vagarosamente esta solução em uma 
mistura fria de $489 \mathrm{cc}$ de ácido nítrico concentrado (não fumegante), (o empregado por nós era de densidade 1,4) e 1148 cc de água distilada. Este reativo emprega-se (1) (4) juntando-se 10 gotas aos $5 \mathrm{cc}$ de extrato aquoso de casca e fervendo-se por alguns minutos em banho-maria.

- cloreto férrico emprega-se em solução saturada, na proporção de 2 gotas para os $5 \mathrm{cc}$ de extrato de casca. Após alguns minutos podese fazer a observação, sem necessidade de se ferver a solução.

Quanto ao cloreto titanoso, quarto e último reagente indicado, não nos foi possível, até o presente, a sua obtenção, motivo porque não o experimentamos.

\section{RESULTADOS OBTIDOS}

Reação de Almen - As colorações obtidas com êste reagente, a-pesar-de não corresponderem totalmente com as observadas por Marloth (4), foram as que melhores resultados deram, dada a constância nas diversas determinações realizadas.

Com êste reativo conseguimos separar as 13 amostras examinadas, em três grupos bem distintos: 1) laranjas agro-sevilhana e agro-doce, que podemos reunir debaixo da designação única - laranja azêda (C. uurantium L.), com uma coloração marrom-clara (fig. 1) ; 2) laranjas caipira e lima $\left(C\right.$. sinensis Osbeck) e limão gigante $\left.{ }^{*}\right)(C$. limonia Osbeck), que apresentam coloração rósea-violeta (fig. 2) ; 3) tôdas as 8 amostras restantes, que dão soluções "quase incolores" (fig. 3). As diferenças notadas entre as espécies e variedades dêste último grupo, são representadas apenas por leves tonalidades, que não podem, a nosso ver, ser consideradas como suficientes para qualquer separação. Além disso, essas tonalidades variam freqùentemente de uma determinação para outra.

A reação de Almen mostrou-se vantajosa pelo fato de os seus resultados terem sido os mesmos, quer usando-se casca de raiz, quer do caule, tanto empregando-se material de "cavalo" (sob laranja doce ou limão eureca), como de pé franco. As variações, quando presentes, eram muito pequenas e em nada influiam nas determinações dos dois primeiros grupos.

Halma e Haas (1) acrescentam ainda, que os seus resultados não foram influenciados pela idade da árvore, época do ano em que foram tiradas as amostras e nem pela variedade enxertada; era indiferente também que a variedade estivesse como "cavalo" ou como enxêrto.

Pelo quadro I, no qual comparamos as colorações obtidas por Marloth (4) com as por nós observadas, podemos ver que, infelizmente, foram grandes as diferenças nos resultados obtidos. Entretanto, entre as poucas confirmações, chamamos atenção para as verificadas com as

(*) Este limão, a-pesar-de dar uma coloração rósea-violeta um pouco mais avermelhada, deve ser incluido neste grupo, pois que a sua identificação é bastante difícil. Pcderemos, entretanto, como veremos mais adiante, separá-lo da laranja doce (caipira e lima) por intermédio do cloreto férrico. 
variedades de limões. Halma e Haas (1), e mais especialmente, Marloth (4), baseando-se nos seus resultados, dizem da possibilidade de se desdobrar a espécie $C$. limonia Osbeck em duas, uma constituida pela variedade limão rugoso e outra, pelas demais variedades, cujos representantes seriam os limões eureca e lisbon.

Pelas nossas observações, que foram realizadas com 6 variedades de $C$. limonia Osbeck, confirmamos a nítida diferença colorimétrica entre os limões rugoso (da Flórida ou nacional) e eureca, bem como, verificamos, de acôrdo com a hipótese acima, que os limões siciliano e gigante devem ser colocados entre as demais variedades do $2 .^{\circ}$ grupo (eureca e lisbon). Apenas teríamos que fazer, em vista do resultado obtido com a variedade ponderosa (que possivelmente não foi examinada pelos citados autores), pequena alteração na constituição dos dois grupos, incluindo esta variedade no grupo do limão rugoso.

Reação do molibdato de amôneo. O molibdato de amôneo, em vista de certos fatos que passaremos a expor, e a-pesar-de ter sido o reagente com o qual mais trabalhamos, foi o que deu os resultados mais negativos.

Tôdas as determinações com êste teste, feitas conforme o método de Halma e Haas (1) usando-se $5 \mathrm{cc}$ de extrato aquoso e 10 gotas do reaçente, foram totalmente inúteis; as soluções apresentavam-se amarelas, com mínimas diferenças de tonalidades.

Sempre preparando novas soluções do reagente, e seguindo com a máxina atenção todos os requisitos julgados necessários e essenciais por Mărloth (4) fizemos muitas outras tentativas, obtendo sempre os mesmos resultados.

A obtenção de bons resultados com êste método reside, segundo Marloth (4), na questão da acidez do reagente; afirma êste autor que "a intensidade da coloração produzida com tôdas as espécies de citrus, depende do reagente ser o mais neutro possível".

Entretanto, como preparássemos o reativo, precisamente de acôrdo com as proporções estabelecidas, era natural que considerássemos a acidez do molibdato, como sendo a desejada, ou, pelo menos, muito próxima dela. Fazíamos, então, como é aconsellhado, a variação dessa acidez, nos diversos ensaios, apenas com a adição de algumas gotas de hidróxido de potássio (a 1C\%).

Em virtude dos resultados sempre contraditórios e da importância atribuida à acidez, resolvemos determinar o pH do nosso reagente. Constatamos, então, contra nossas espectativas, ser impossível fazər-se a determinação do $\mathrm{pH}$, tal a quantidade de ácido que o reagente continha.

Supondo, naturalmente, que a causa dos nossos insucessos fôsse devida a essa excessiva quantidade de ácido (excesso êsse, possìvelmente proveniente da maior concentração do ácido por nós usado), experimentamos ainda novas determinações com êste reagente, modificando-o, porém, de maneira a obtê-lo com uma acidez próxima do neutro. Depois de algumas tentativas, sòmente conseguimos obtê-lo nestas con- 


\section{QUADRO I}

COMPARAÇAO ENTRE AS COLORAÇŌES OBTIDAS POR MARLOTH E POR NÓS, COM A REAÇA DE ALMEN

\begin{tabular}{|c|c|c|c|}
\hline \multicolumn{2}{|c|}{ Resultados de Marloth } & \multicolumn{2}{|c|}{ Resultados nossos } \\
\hline Amostras & Colorações & Amostras & Colorações \\
\hline $\begin{array}{l}\text { Sour Orange } \\
\text { (Bitter Seville) }\end{array}$ & light brown & $\begin{array}{l}\text { Agro-doce e } \\
\text { agro-sevilhana }\end{array}$ & marrom-clara \\
\hline Sweet Orange & pink & $\begin{array}{c}\text { Laranja lima e } \\
\text { caipira }\end{array}$ & róseo-violeta \\
\hline Lime & light pink & $\begin{array}{l}\text { Lima da Pérsia } \\
\text { e limão cravo }\end{array}$ & quase incolor \\
\hline $\begin{array}{l}\text { Tangerine } \\
\text { (Naartjie) }\end{array}$ & almost colorless & Tangerina cravo & quase incolor \\
\hline Grapefruit & light brown pink & Pomelo & quase incolor \\
\hline Rough lemon & almost colorless & $\begin{array}{l}\text { Limões rugosos } \\
\text { da Flórida e } \\
\text { nacional }\end{array}$ & quase incolor \\
\hline \multirow{3}{*}{ Lemon } & \multirow{3}{*}{ dark brown } & Limãc ponderosa & quase incolor \\
\hline & & Limão gigante & $\begin{array}{l}\text { róseo-violeta } \\
\text { (avermelhada) }\end{array}$ \\
\hline & & $\begin{array}{c}\text { Limões eureca } \\
\text { e siciliano }\end{array}$ & $\begin{array}{l}\text { marrom-escura } \\
\text { (avermelhada) }\end{array}$ \\
\hline P. trifoliata & $\begin{array}{l}\text { almcst colorless } \\
\text { (green tint) }\end{array}$ & P. trifoliata & quase incolor \\
\hline Citron & very light brown & Cidra & quase incolor \\
\hline Shaddock & $\begin{array}{l}\text { almost colorless } \\
\text { (purple tint) }\end{array}$ & Toranja melancia & marrom-clara \\
\hline Kunquat & $\begin{array}{l}\text { almost colorless } \\
\text { (green tint) }\end{array}$ & Kunquat Nagami & quase incolor \\
\hline Tangelo & light pink & Tangelo & róseo-violeta \\
\hline Citrange & light pink & Citrangequat & marrom-violeta \\
\hline Limequat & light brown & - & - \\
\hline Citrus mitis & deep pink & $\ldots$ & - \\
\hline
\end{tabular}


dições (com pH $=6,5$ ), fazendo uma modificação acentuada na segunda solução, que passou a ser preparada com $160 \mathrm{cc}$ de ácido nítrico (densidade $=1,4$ ) a $30 \%$ e $400 \mathrm{cc}$ de água. Os resultados obtidos com êste novo reagente, cuja quantidade de ácido foi, aproximadamente, 4,5 vêzes menor do que a indicada, não foram, no entanto, mais vantajosos que os anteriores.

Insistindo ainda, com as nossas tentativas, fizemos as mais variadas e profundas alterações no método, como, por exemplo, o emprêgo simultâneo do molibdato com violeta gentiana e sulfato de cobre. E, entre os resultados obtidos com estas modificações, alguns mostraram-se bastante interessantes, pelo fato de terem sido os que mais se aproximaram dos desejados. A coloração azul escura com o limão rugoso, que, segundo Marloth (4), é uma das maiores dificuldades, foi conseguida em muitas das combinações acima. Estes resultados, que seriam suficientes para a identificação de mais algumas variedades ainda não determinadas, continuaram, entretanto, sem utilidade prática, dada a enorme variabilidade dos mesmos nas diversas repetições.

Dêste modo, se bem que os resultados assim obtidos fôssem menos desanimadores, decidimos não prosseguir nos nossos trabalhos com êste reativo, em vista da dificuldade de obtenção de material, que se tornava cada vez mais acentuada. Esta dificuldade deriva, como dissemós no início do presente trabalho, do fato da maioria dos "cavalos" necessários pertencer a ensaios experimentais.

Reação do cloreto férrico. Com tôdas as espécies e variedades, êste reagente dá uma coloração marrom, formando série, cujos têrmos se diferenciam por pequenas variações na intensidade da côr e pela formação ou não de mínimas quantidades de precipitado. Sòmente as diferenças entre os têrmos extremos desta série, podem ser, portanto, consideradas como úteis.

Dêste modo, as determinações com o cloreto férrico seriam valiosas, em combinação com os resultados obtidos pelo emprêgo dos reagentes anteriores. Seria um reativo auxiliar do de Almen e do molibdato de amôneo.

Como, porém, os reativos anteriores não deram resultados plenamente satisfatórios, o cloreto férrico tornou-se, para nós, de pequenas possibilidades práticas. Salientamos, entretanto, entre os resultados obtidos, os constatados com a laranja doce (caipira e lima) (Fig. 5) e limão gigante (Fig. 6), que se acham representados no quadro II. Estas duas espécies, que pelo reativo de Almen são grupadas, podem, agora, ser separadas e identificadas. $\left({ }^{*}\right)$

(") Como a laranja lima não constitue ainda um "cavalo" comercialmente conhecido e, dada a posição exatamente oposta da laranja caipira nesse particular, podemos, com probabilidades mínimas de êrro, considerar como caipira, tôda a amostra que der a coloração rósea-violeta com o Almen e marrom-clara com o cloreto férrico. 


\section{QUADRO II}

\section{RESULTADOS DE INTERÊSSE PRÁTICO OBTIDOS COM O CLORETO FÉRRICO}

\begin{tabular}{|c|c|}
\hline Espécies e variedades & Colorações \\
\hline $\begin{array}{l}\text { Laranja doce } \\
\text { (Caipira e lima) }\end{array}$ & $\begin{array}{c}\text { marrom } \\
\text { (bastante turva) }\end{array}$ \\
\hline $\begin{array}{c}\text { Limões eureca, siciliano } \\
\text { e gigante }\end{array}$ & $\begin{array}{l}\text { marrom-escura } \\
\text { (límpida) }\end{array}$ \\
\hline $\begin{array}{l}\text { Limões ponderosa e rugosos da } \\
\text { Flórida e nacional }\end{array}$ & $\begin{array}{l}\text { marrom-clara } \\
\text { (pouco turva) }\end{array}$ \\
\hline
\end{tabular}

Com relação à hipótese formulada por Mârloth (4) a respeito da separação da espécie $C$. limonia Osbeck em duas, nada temos a acrescentar, pois tôdas as considerações feitas ao tratarmos da reação de Almen, foram confirmadas pelos resultados aquí verificados (quadro II).

\section{CONCLUSÕES}

Do exposto, podemos concluir que, em nosso meio, a identificação colorimétrica dos "cavalos" de Citrus não apresenta as mesmas possibilidades que as obtidas em outros paises.

Apenas os reagentes de Almen e o cloreto férrico deram algum resultado, permitindo identificação de algumas das diversas espécies e variedades. Dado, porém, o fato feliz para nós, dêstes reagentes permitirem, com certa segurança, a identificação dos "cavalos" azêda e caipira, êles se apresentam bastante úteis, pois os nossos pomares são, na sua grande maioria, enxertados em um dêstes dois "cavalos".

Como resumo dos nossos resultados, damos, no quadro III, todos os dados julgados valiosos e de reais possibilidades na identificação colorimétrica. Como foi observado no texto, sòmente levamos em consideração, neste quadro, as espécies e variedades, que possam ser encontradas como "cavalo" em nosso Estado.

\section{QUADRO III}

\begin{tabular}{c|c|c}
\hline Espécies e variedades & Reação de Almen & Reação do cloreto férrico \\
\hline Laranja azêda & marrom-clara & máseo-violeta \\
\hline $\begin{array}{l}\text { Laranja doce } \\
\text { (Caipira e lima) }\end{array}$ & $\begin{array}{l}\text { marrom } \\
\text { (bastante turva) }\end{array}$ \\
\hline Limáo gigante & $\begin{array}{l}\text { marrom-escura } \\
\text { (límpida) }\end{array}$ \\
\hline $\begin{array}{c}\text { As } 8 \text { restantes } \\
\text { espécies e variedades }\end{array}$ & quase incolor & \\
\hline
\end{tabular}




\section{AGRADECIMENTOS}

O autor agradece ao sr. Coarací M. Franco, pelos valiosos auxílios prestados na execução dêste trabalho; aos srs. Sílvio Moreira, Antônio José Rodrigues Filho e Felipe W. C. de Vasconcelos, pela obtenção do material.

\section{SUMMARY}

In order to study the susceptibility of the various stocks with regard to the new disease "tristeza" ("sadness"), a quick and acurate identification of the stock is required. In orchards this cannot be done in most cases as stocks do not always exhibit sprouts and on account of erroneus information frequently given by owners.

We have tested the colorimetric identification, already employed in other countries. This identification is based on the differences of color obtained in the watery extract of the bark taken from the trunk or from the root, when treated by special reagents.

The results obtained are somewhat different from those described by the authors of the method. This is perhaps due to variation in environmental conditions.

Only the Almen and ferric chloride tests gave satisfactory results, making it possible to arrange the species and varieties examined into four groups: (1) C. aurantium L. ; (2) C. sinensis Osbeck; (3) C. limonia Osbeck ("gigante" variety) and (4) all the others.

Although deficient in certain respects the test is valuable, permiting us to identify the stocks of orange trees, azeda as well as caipira the most employed in the citrus orchards of the State of S. Paulo.

\section{LITERATURA CITADA}

1. Halma, F. F. e A. R. C. Haas. Identification of certain species of citrus by colorimetric tests. Plant Physiology 4:265-68. 1929.

2. Halma, A. F. Scion influence in citrus. The Jour. Pomol. and Hort. Sci 12:99-104. 1934.

3. Hendriksen, H. C. Identification of citrus budding stock : Porto Rican method for testing root system. Florida Grower 36:14-15. 1928.

4. Marloth, R. H. Notes on colcrimetric tests for ctrus species. The Jour. Pornol. and Hort. Sci. 14:1-8. 1936. 


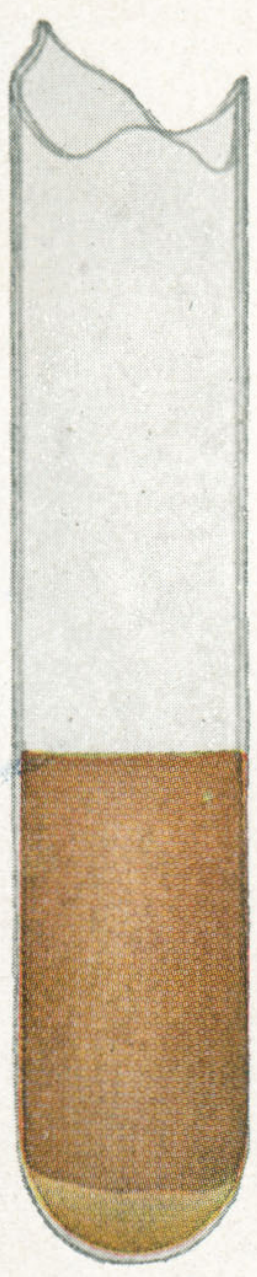

Fig. 1

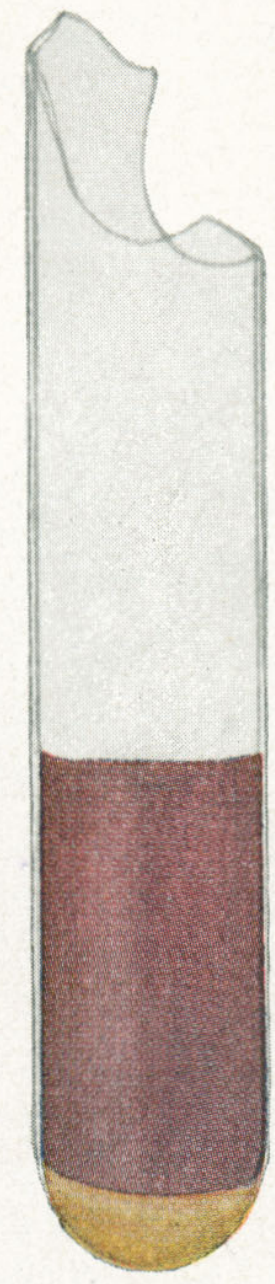

Fig. 2

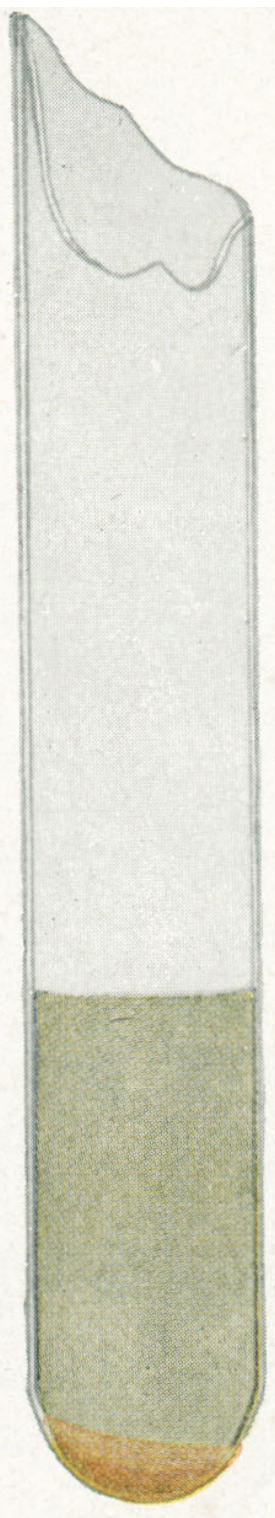

Fig. 3

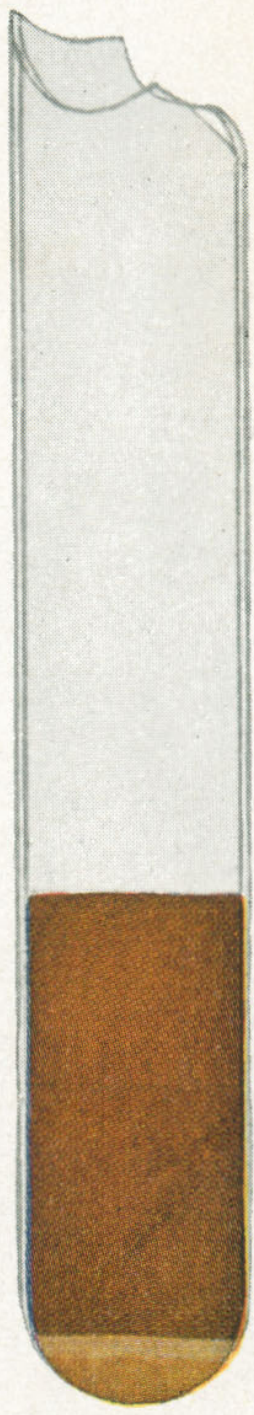

Fig. 4

\section{Colorações obtidas com reagente de Almen}

Fig. 1 - Laranja azêda (C. aurantium L.)

Fig. 2 - Laranja caipira (C. sinensis Osbeck)

Fig. 3 - Limão rugoso da Flórida (C. limonia Osbeek)

Fig. 4 - Limão siciliano (C. limonia Osbeck) 


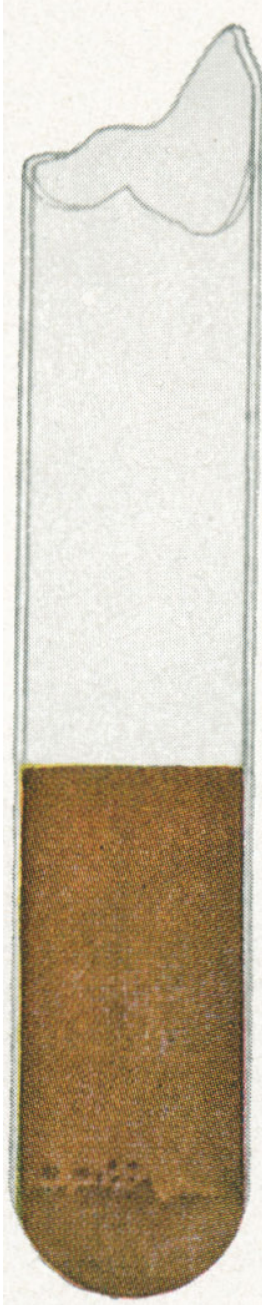

Fig. 5

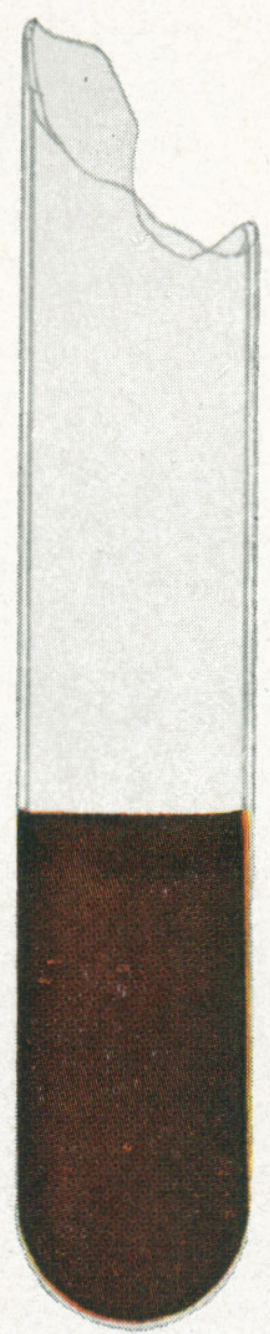

Fig. 6

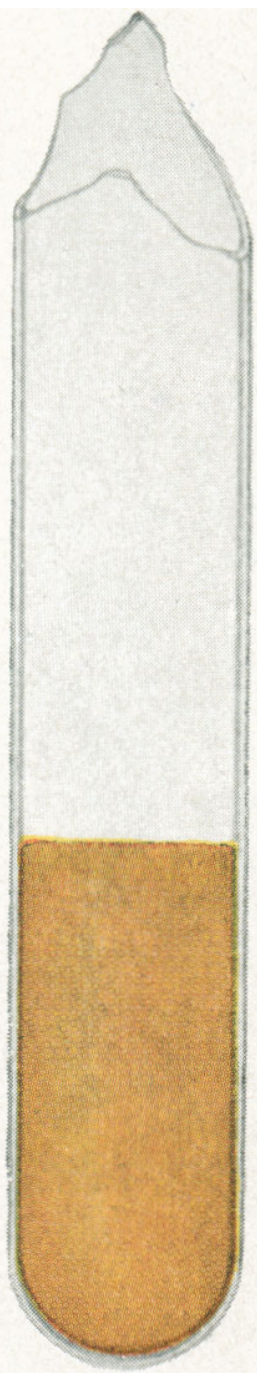

Fig. 7

Coloraçōes obtidas com o cloreto férrico

Fig. 5 - Laranja caipira (C. sinensis Osbeck)

Fig. 6 - Limão gigante (C. limonia Osbeck)

Fig. 7 - Limão rugoso da Flórida (C. limonia Osbeck) 